4th Global Business Research Congress, May 24-25, 2018, Istanbul, Turkey.

\title{
THE EFFECT OF ISA 570 GOING CONCERN ON AUDIT REPORTS
}

\author{
DOI: 10.17261/Pressacademia.2018.911 \\ PAP- V.7-2018(64)-p.339-343
}

Oktay Tas ${ }^{1}$, Huseyin Mert ${ }^{2}$, Memet Guner ${ }^{3}$, Goktug Duyar ${ }^{4}$

${ }^{1}$ Istanbul Technical University, Istanbul, Turkey.

tasokta@itu.edu.tr, ORCID: 0000-0002-7570-549X

${ }^{2}$ Okan University, Istanbul Turkey.

huseyin.mert@okan.edu.tr, ORCID: 0000-0001-5391-7865

${ }^{3}$ Okan University, Istanbul, Turkey.

memetguner73@gmail.com, ORCID: 0000-0002-0193-7706

${ }^{4}$ Okan University, Istanbul, Turkey.

gokduyar@yahoo.com, ORCID: 0000-0003-2246-4909

To cite this document

Tas, O., Mert, H., Guner, M., Duyar, G. (2018). The effect of ISA 570 going concern on audit reports. Press Academia Procedia (PAP), V.7, p.339-343.

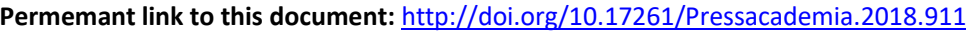

Copyright: Published by PressAcademia and limited licenced re-use rights only.

\section{ABSTRACT}

Purpose- The aim of the study is to understand going concern issue, to reveal the importance of going concern disclosures in audit reports for both company managements and investors, and to raise an opinion how going concern needs to be discussed in audit reports. Methodology- International Standards on Auditing (ISA) 570 "Going Concern" was studied, and its effect to audit reports analyzed. Findings- It is revealed going concern was emphasized in the audit reports of the companies studied, but necessary amount of disclosures were not found. Also, in some examples, it was coincided auditors' opinions were not appropriate with the going concern issue.

Conclusion- The effect of ISA 570 "Going Concern" on audit reports was analyzed. It was determined whether the companies can go on with their businesses or not, and it is revealed auditors should take going concern issue into account seriously in their opinions.

Keywords: Audit standarts, ISA 570, going concern.

JEL Codes: M40, M41, M42

\section{BDS 570 işLETMENIN SÜREKLILIĞi STANDARDININ DENETIM RAPORLARINA ETKISi}

\section{ÖZET}

Amaç- Bu çalışmada genel olarak, işletmelerde süreklilik varsayımının anlaşııması, işletmelerin sürekliliğe dair açıklamalara bağımsız denetim raporlarında yer verilmesinin işletme yönetimi ile yatırımcı açııından önemini ortaya çıkarmak ve bağımsız denetim raporlarında sürekliliğin ne şekilde işlenmesi gerektiğine dair bir kanı oluşturulması hedeflenmiştir.

Yöntem- Bağımsız Denetim Standardı 570 İşletmenin Sürekliliği Varsayımı genel olarak incelenerek Bağımsız Denetim Raporlarına etkisi ve önemi analiz edilmiştir.

Bulgular- İncelenen işletmelerin Bă̆ımsız Denetim Raporlarında süreklilik varsayımına yer verildiği görülmüş olmakla beraber, bu konuya yeterince açıklama getirilmediği saptanmıştır. Süreklilik kavramına uygun olarak denetçi görüşü verilmediği örneklere de rastlanmıştır.

Sonuç- Bu çalışmada, Bağımsız Denetim Standardı 570 İşletmenin Sürekliliği Varsayımı́nın bağımsız denetim sürecine ve finansal tablolara etkisi ve önemi incelenmiştir. İșletmenin faaliyetlerini sürdürüp sürdürmeyeceğinin saptanması ve bu hususun finansal tablolara etkisinin bağımsız denetimde denetçinin dikkate alması gereken önemli bir konu olduğu görülmüştür.

Anahtar Kelimeler: Denetim standartları, ISA 570, işletmenin sürekliliği.

JEL Kodları: M40, M41, M42

\section{GiRiş}

Uluslararası denetim standartları denetim sürecinde denetçinin işletmenin sürekliliği varsayımınında denetlenmesini zorunlu tutar. İsletmenin sürekliliği kavramına ilk olarak, Amerikan Muhasebe Standartları Kurulu olan FASB tarafından 1953 yılında yayınlanan ARB 43 "Restatement and Revision of Accounting Research Bulletins" te işletmelerin sürekliliğine değinilmiştir. Amercan menkul Kıymetler ve Borsa Komisyonu (SEC) tarafından 1962 yılında ASR 90 "Accounting Series Release" yayınlanmış olup bu düzenleme ile işletmelerde süreklilik 
değerlendirmesi yapılması ifade edilmiştir. AICPA, 1974 yılında SAS 2'yi yayınlamış, işletmenin sürekliliğinin değerlendirilmesinde dikkat edilecek hususlar açıklanmıştır. Yayınlanan SAS 59'da ise işletmenin sürekliliğinin belirlenmesinde şu üç husus belirlenmiştir;

- Denetçi her denetim sözleşmesi tarihinde müşterisinin sürekliliğini göz önünde bulundurması,

İşletmenin sürekliliği hakkında önemli bir şüphe varsa denetçi bu durumu raporunda açıklaması ve

Denetçinin raporunda önemli şüpheyle ilgili bir açıklama paragrafı yer almasıdır.

Belirli aralıklarla düzenlemeler devam etmiştir. Uluslararası Muhasebeciler Federasyonu (IFAC) 570 nolu "İşletmenin Sürekliliği” standardını yayınlamıştır. Buna göre denetçilerin denetlenen işletmelerin süreklilik durumlarını değerlendirmeleri gerekmektedir. Uluslararası Muhasebe Standartları Kurulu (IASB) tarafından yayınlanan UMS 1 "Finansal Tabloların Sunumu" de süreklilik kavramına değinilmiş olup finansal tablolarda da sürekliliğin belirlenmesine dair çalışma yapılmasına değinilmiştir. Kamu Gözetimi Kurumu (KGK) tarafından 23 Ocak 2014 tarihinde Resmi Gazete'de yayımlanan “işletmenin Sürekliliği (BDS 570) Hakkında Tebliğ, Türkiye Denetim Standartları Tebliği No:25” çerçevesinde borsaya kote olan ve borsaya kote olup daha sonra iflas etmiş şirketlerin Bağımsız Denetim Raporları'nda işletmenin sürekliliğine dair açıklamaları incelenerek, bu açıklamalardan örnekler verilmiştir.

İşletmenin sürekliliği kavramı; "işletmelerin faaliyetlerini bir süreye bağlı olmaksızın sürdüreceğini ifade eder. Bu nedenle işletme sahiplerinin ya da hissedarlarının yaşam süreleriyle bağlı değildir. Iş̧letmenin süreklilik kavramı maliyet esasının temelini oluşturur." (1 no.lu Muhasebe Sistemi Genel Tebliği)

İşletmenin Sürekliliği; " Yönetim, mali tabloları hazırlarken faaliyetlerini süresiz sürdüreceğini dikkate alır. Yönetimin şirketi tasfiye etme veya ticari faaliyetini sona erdirme veya bunların yerine geçecek daha gerçekçi bir alternatifi yoksa, mali tablolar süreklilik kavramına göre düzenlenir." (UMS 1.23)

İ̧̧letmenin Süreklilik Varsayımı, “iş̧letmenin süreklilik varsayımı uyarınca, işletmenin öngörülebilir gelecekte faaliyetlerini sürdüreceği kabul edilir. Yönetim işletmeyi tasfiye etmeyi veya faaliyetleri durdurmayı planlamadıkça ya da yönetimin başkaca gerçekçi bir alternatifi bulunmadıkça, genel amaçlı finansal tablolar işletmenin süreklilik varsayımı kullanılarak hazırlanır." (BDS 570 Hakkında Tebliğ, Türkiye Denetim Standartları Tebliği No:25, 2.madde)

Bağımsız denetim raporu hazırlayan denetçilerin sorumluluğuna da tebliğin altıncı maddesinde yer verilmiştir. Şöyle ki; “Denetçinin sorumluluğu, finansal tabloların hazırlanmasında yönetimin kullandığı işletmenin sürekliliği varsayımının uygunluğu hakkında yeterli ve uygun denetim kanıtı elde etmek ve işletmenin sürekliliğinin devamına ilişkin önemli bir belirsizliğin var olup olmadığı konusunda bir sonuca varmaktır. Bu sorumluluk, finansal tabloların hazırlanmasında kullanılan finansal raporlama çerçevesi işletmenin sürekliliğinin devamına ilişkin yönetimin özel bir değerlendirme yapması hususunda açık bir hüküm içermese dahi, mevcuttur." Tebliğin devamı olan 7. madde de ise “Ancak, BDS 2002'de açıklandığı gibi denetçinin önemli yanlışlıkları tespit etme becerisi üzerindeki yapısal kısıtlamaların muhtemel etkileri, işletmenin sürekliliğinin devamını sona erdirebilecek gelecekteki olay veya şartlar söz konusu olduğunda daha büyüktür. Denetçi gelecekteki bu tip olay veya şartları önceden tahmin edemez. Dolayısıyla denetçi raporunda işletmenin sürekliliğine ilişkin belirsizliğe atıfta bulunulmaması, işletmenin sürekliliğinin devamı açısından bir güvence olarak kabul edilemez." Denetçinin raporunda işletmenin sürekliliğine ilişkin belirsizlik ile ilgili atıfta bulunmamasının işletmenin sürekliliği ile ilgili bir güvence oluşturmadığından denetçinin sorumluluğu bu noktada azalmaktadır.

Son olarak International Auditing and Assurance Standards Board (IAASB) tarafından 15 Ocak 2015 tarihinde yeni denetçi raporu ile ilgili denetim standartları yayınlanmıştır. Bu denetim standartları borsada işlem gören tüm işletmelerin denetiminde geçerli geçerlidir. Bu denetim standartlarının süreklilik ile ilgili kısmı şöyledir;

- Işletmenin sürekliliği ile ilgili hem denetçinin hem de yönetimin sorumluluklarına ilişkin daha fazla açıklamaya yer verilmesi,

- $\quad$ İşletmenin sürekliliğine ilişkin önemli bir belirsizlik olması durumunda bu konu ile ilgili denetçi raporunda ayrı bir bölüm verilmesi,

- Iş̧letmenin sürekliliğine ilişkin önemli bir belirsizlik bulunmadığı halde işletmenin sürekliliği varsayımını tehlikeye düşürecek göstergelerin olması durumunda bu hususun da denetçi raporunda açıklanması,

\section{LITERATÜR INCELEMESI}

Süreklilik Varsayımı'nın tanımı ve denetçinin raporunda süreklilikle ilgili nasıl bir tutum izlemesi gerektiğine dair kurumlar ve kişiler tarafından yapılmış açıklamalara aşağıda yer verilmiştir.

Sürekli şekilde devam eden kavramı, işletme yükümlülüklerinin yerine getirilmesine veya varlıklara ait edinim bedellerinin tahmin edilen süre içerisinde azar azar tüketilmesine imkân veren bir dönemi anlatır (Devlet Planlama Teşkilatı, Muhasebenin Temel Kavramları ve Genel Kabul Görmüş Muhasebe Prensipleri, 1970, s.18). İşletmelerin faaliyetleri, süreçleri, paydaşları, paydaşların işletmeden beklentileri birbirinden farklı olduğundan bunların yansımalarını içeren sürdürülebilirlik raporlarının içeriği de işletmelere göre farklılaşmaktadır (Çalışkan, 2012, s. 156).

Süreklilik Varsayımı, Türkiye Muhasebe Standartlarının birincisinde 25 inci ve 26. paragrafları ile onuncu standardın 14,15 ve 16 . paragraflarında açıklanmıştır. Bu paragraflara göre; işletme yönetimi, finansal tabloları düzenlerken işletmenin faaliyetlerini süreklilik içerisinde devam etme yetisini değerlendirir. Yönetimin şirketi tasfiye etme veya ticari faaliyetini sona erdirme niyeti veya mecburiyeti yoksa finansal tablolar süreklilik kavramına düzenlenir. Yönetim, değerlendirmeleri yaparken işletme faaliyetlerinin sürekliliğine kuşku düşürecek önemli belirsizlikler taşıyan olaylar veya koşulların farkındaysa, bu belirsizlikleri açıklar. İşletme, finansal tablolarını süreklilik 
esasına göre hazırlamaması halinde, bu hususu, finansal tablolarını düzenlemesi sırasında dayandırdığı temel ve işletmenin süreklilik arz etmeyecek şekilde değerlendirilmesinin nedeni ile birlikte açıklar.

İşletmelerde süreklilik değerlendirmesi, çok ciddi düzeyde mesleki yargı gerektirmektedir. Bu yargı müşteri işletmenin finansal ve faaliyetsel bilgileriyle oluşmaktadır. Bu nedenle işletmenin sağladığı bilgiler işletmenin sürekliliğinin değerlendirilmesinde yeterli değilse, hata olasılığı yükselmektedir. Bu durum da, yanlış bir sonuca ulaşmaya götürmektedir. Böyle bir hata riski, denetçiye bir maliyet yükü de getirmektedir. Çünkü denetçi; denetimin yapısını, kapsamını ve zamanlamasını buna göre ayarlamak zorundadır. (Geiger, M.A. \& Rama, D.V, 2006).

Denetim kanıtlarının incelenmesinden sonra denetçi yönetimin işletme sürekliliğine ilişkin çalışma yapıp yapmamasına göre farklı iki yol izler.

Yönetim, sürekliliğe ilişkin bir çalışma yapmışsa; işletme sürekliliğine ilişkin değerlendirmede, yönetimin varsayımları tartışılacak ve süreklilik ile ilgili ciddi şüphe uyandıracak olaylar ve durumlar olup olmadığı araştırılır. Bu çalışmada yönetimin sürekliliği ele alış yöntemleri de incelenmelidir. Belirsizliğe ilişkin sonuca ulaşıldıktan sonra denetçi raporunu düzenler.

Eğer yönetim, sürekliliğin değerlendirilmesine ilişkin bir çalışma yapmamışsa; denetçi, yönetimle birlikte işletmenin sürekliliği varsayımının amacı ve gerekçelerini tartışmalıdır. İşletmenin sürekliliği değerlendirme yeteneği ve sürekliliği engelleyen durum ve hususların tespitine yönelik soruşturma çalışması yapar. (Tepegöz, Türedi, 2006)

Mali tablolar normalde öngörülebilen bir süre içinde işletmenin sürekliliği varsayımı ile düzenlenirler. Iş̧letme yönetiminin işletme faaliyetlerini durdurmak gibi bir niyetinin olmadığı ve bunu zorlayan koşulların da olmadığı varsayılır. Bu varsayımı tamamlayan başka bir varsayım ise dönemsellik varsayımıdır. Oysa bilanço tarihlerinde işletmenin faaliyetleri durmamakta, sürmektedir. Ancak, işletmenin faaliyetlerinden sonuç çıkartabilmek ve alınacak önlemleri belirleyebilmek için işletmenin sonsuz ömrü daha kısa sürelere bölünmektedir (Kaval, 2005, s.161).

Bu noktada anlatılmak istenen, mali tablolar işletmenin öngörülebilir bir sürede faaliyetlerini devam ettireceği varsayımı ile hazırlanır. Örneğin işletmenin sonsuz olan ömrü beşer yıllık planlara ayrılarak, gelişiminin gözlemlenmesi ve oluşacak sorunlar konusunda tedbir alınması sağlanır.

İşletmenin sürekliliğini olumsuz etkileyecek çeşitli olay ve işlemler olabilir. İşletmenin sürekliliğini tehlikeye sokan etmenlere şu örnekler verilebilir (Güredin, 2010, s. 75).

1- Tekrarlanan faaliyet zararları ve çalışma sermayesi açıkları,

2- İşletmenin vadesi gelen borçlarını ödeme güçlüğü içinde olması,

3- Önemli müşteri kayıpları, su baskını, deprem gibi sigortalanmamış doğal afetlerin meydana gelmiş olması,

4- Önemli yönetici ve kilit personel kaybı,

5- $\quad$ İşletmenin faaliyetlerini tehlikeye sokabilecek hukuki dava gibi olayların olması vb.

Denetçi, işletmenin sürekliliğine ilişkin ciddi şüphe uyandıracak olaylar, koşullar ve işletme riskleriyle ilgili durumlar olup olmadığını değerlendirmelidir. Şüphe uyandıracak olaylardan bazıları aşağıdaki gibi olabilir: (Kavut,Taş,vd.2009, s.171)

- İşletmenin kısa vadeli varlıklarının kısa vadeli borçlarını karşılayamama durumu,

- Gerçekçi yenileme veya ödeme ihtimalleri olmayan ve ödeme tarihleri yaklaşan borçların olması,

- Alacaklıların ve diğer borç verenlerin finansal desteklerini çekebileceklerine ilişkin belirtiler,

- Cari veya gelecek dönemlere ait finansal tablolarda faaliyetlerden kaynaklanan nakit akışlarının negatif olması,

- Gösterge niteliğindeki finansal oranların olumsuzluğu,

- Kredi anlaşmalarının koşullarına uyulamaması,

- Önemli yeni ürünlerin geliştirilmesi veya diğer önemli yatııımların gerçekleştirilmesi için gerekli finansmanın sağlanamaması,

- Yönetim kademesindeki önemli pozisyonların boşalmasının ardından yerlerinin doldurulamaması,

- Büyük bir pazarın, satış zincirinin, lisansın veya başlıca tedarikçilerden birinin kaybedilmesi,

- İşçilerle yaşanan zorluklar veya önemli malzemelerde yaşanan kıtlık

- Sermaye gerekliliklerine veya yasal gerekliliklere uymama,

- Kaybedilirse işletmenin karşılayamayacağı taleplerle sonuçlanabilecek, işletme aleyhine açılmış yasal veya idari işlemler,

• Işletmeyi kötü yönde etkilemesi beklenen, kanun veya hükümet politikası değişiklikleri. 
İ̧̧letmenin sürekliliğini etkileyen bu gibi durumlar denetçinin bağımsız denetim raporunda vereceği görüşü de etkileyecektir. Kısaca özetlersek (Socol, 2010, s. 295);

\begin{tabular}{|l|l|l|l|}
\hline Süreklilik Varsayımı & Kanıt Durumu & Finansal Tablo Açıklamaları & Denetçinin Görüşü \\
\hline Uygun & Bulunmuyor & Uygun & Şartsız Görüş \\
\hline Uygun & Bulunuyor & Uygun & $\begin{array}{l}\text { Şartsız Görüş (Denetçi raporda bu } \\
\text { konuya dikkat çeken açıklamada } \\
\text { bulunmalıdır) }\end{array}$ \\
\hline Uygun & Bulunuyor & Açıklamalar Yapılmamış & Şartlı yada Olumsuz Görüş \\
\hline Uygun Değil & Bulunuyor & Önemsiz & Olumsuz Görüş \\
\hline Uygun Değil & $\begin{array}{l}\text { Kanıtlar finansal tabloları } \\
\text { önemli ölcüde etkiliyor }\end{array}$ & Önemsiz & Görüş Vermekten Kaçınma \\
\hline
\end{tabular}

\section{FINANSAL TABLOLAR VE BAĞIMSIZ DENETIM RAPORLARINDA SÜREKLILIĞE DAIR AÇIKLAMALAR}

Temelde incelediğimiz BisT'te işlem gören/görmüş dört firmanın beş yıllık finansal tabloları ve Bağımsız Denetim Raporları detaylı bir şekilde ele alınmış ve aşağıda belirtilen bulgulara ulaşıımıştır;

- Genel olarak işletmelerin bağımsız denetim raporları ve finansal tablolarında işletmenin süreklilik kavramı kısaca dikkate alınmıştır. Örneğin, "Grup konsolide finansal tablolarını işletmenin sürekliliği ilkesine göre hazırlamıştır." Denilmiş olup ayrıntıya girilmemiştir.

- Ş̧irketlerin finansal durumlarının oluşturduğu sürekliliği etkileyen faktörlerin denetim standardına uygunluğu, denetçinin şartlı görüş ya da olumlu görüş olarak vermesiyle sonuçlanmıştır.

- $\quad$ Işsletmenin sürekliliği kavramını olumsuz etkileyecek faktörlerin bulunmasına rağmen olumlu görüş verilen ve sonrasında ilgili şirketin iflasıyla sonuçlanan durumlara da rastlanmıştır.

- Denetçi raporunda sürekliliğe ilişkin sorunlar gördüğünde ve bu durumu raporunda belirttiğinde, denetim şirketinin değiştirildiğine de rastlanılmıştır.

İncelenen işletmelerin bir kısmının iflas etmiş olduğu da göz önüne alındığında sürekliliğe ait açıklamaların ne derece önemli olduğu anlaşılmaktadır.

\section{SONUÇ}

İşletmenin Sürekliliği (BDS 570) Hakkında Tebliğ, Türkiye Denetim Standartları Tebliği No:25'de 2.maddesinde belirtildiği şekilde İşletmenin süreklilik varsayımı uyarınca, işletmenin öngörülebilir gelecekte faaliyetlerini sürdüreceği kabul edilir. Yönetim işletmeyi tasfiye etmeyi veya faaliyetleri durdurmayı planlamadıkça ya da yönetimin başkaca gerçekçi bir alternatifi bulunmadıkça, genel amaçlı finansal tablolar işletmenin süreklilik varsayımı kullanılarak hazırlanır. Buradan hareketle işletmeler mali tablolarını, işletmenin öngörülebilir bir gelecekte de faaliyetlerine devam edeceği varsayımına dayanarak düzenler. İşletme yönetiminin işletme sürekliliğine ilişkin varsayımının denetçi tarafından onaylanması gerekir. Denetçi değerlendirmeyi denetim kanıtlarına göre yapacaktır.

Örneklerde incelenen şirketler açısından bakıldığında, bağımsız denetim raporlarında genel olarak işletme sürekliliğine dair başlıkların açıldığı görülmektedir. Ama açılan bu başlıkların altında bu konudan kısaca bahsedilmekte ve yeterince açıklayıcı bilgi verilmediği görülmektedir. Şirketlerin çoğunda kısa bir şekilde "Grup konsolide finansal tablolarını işletmenin sürekliliği ilkesine göre hazırlamıştır." denilerek açıklanmıştır. Ayrıca, denetçi raporunda sürekliliğe ilişkin sorunlar gördüğünde ve bu durumu raporunda belirttiğinde genellikle denetim şirketinin değiştirildiğine rastlanılmaktadır.

Sonuç olarak denetçi bağımsız denetim raporunda işletmenin sürekliliğine ilişkin detaylı bir inceleme yapmalı ve elde ettiği bulguları değerlendirerek raporunda işletmenin sürekliliğine dair öngördüğü hususları belirtmelidir. Bilinmelidir ki işletmenin sürekliliği ile ilgili risklerin ciddi bir şekilde ortaya konması şirketin geleceği ve ilişkili yatırımcılar açısından son derece önemlidir.

\section{KAYNAKLAR}

Geiger, M. A., Rama, D. V. (2006). Audit firm size and going-concern reporting accuracy. Accounting Horizons, 20(1), 1-17.

Kaval, H. (2005). Muhasebe denetimi (2. Baskı). Ankara: Gazi Kitabevi.

Güredin, E. (2010). Denetim ve güvence hizmetleri (13. Baskı). İstanbul: Türkmen Kitabevi.

Çalışkan, A. O. (2012). İşletmelerde sürdürülebilirlik muhasebe mesleği ilişkisi. Mali Çözüm Dergisi, 112(2012), 133-157.

Devlet Planlama Teşkilatı (1970). Muhasebenin temel kavramları ve genel kabul görmüş muhasebe prensipleri. 1970 , s.18.

İşletmenin Sürekliliği (BDS 570) Hakkında Tebliğ, Türkiye Denetim Standartları Tebliği No:25. 
International Auditing and Assurance Standards Board (IAASB)

Socol (2010). Significant doubt about the going concern assumption in audit. Annales Universitatis Apulensis Series Oeconomica, 12(1).

Kavut, Taş, Şavlı (2010). Uluslararasi denetim standartlari kapsaminda bağimsiz denetim. ISMMMO, 130.

Amercan menkul Kıymetler ve Borsa Komisyonu (SEC) (1962). Accounting Series Release.

Tepegöz, Türedi (2015). İşletmenin sürekliliği varsayımı ve denetçinin sorumluluğu. Erzincan Üniversitesi Sosyal Bilimler Enstitüsü Dergisi (ERZSOSDE) VIII-II: 43-52.

Amerikan Muhasebe Standartları Kurulu olan FASB (1953) ARB 43 "Restatement and Revision of Accounting Research Bulletins". 